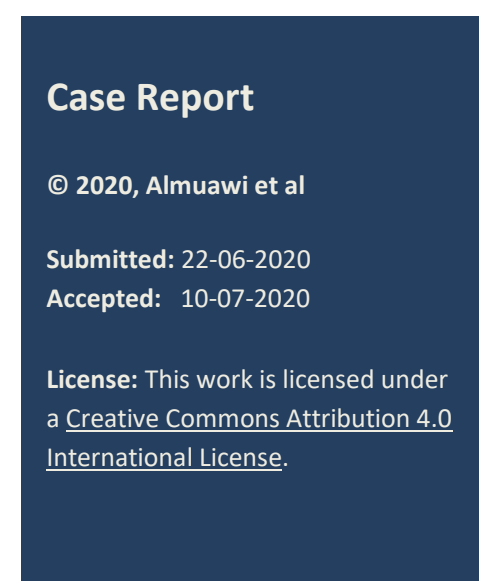

\section{Giant pedunculated hepatic hemangioma necessitating surgical excision in a neonate: A case report}

\author{
Abdulrahman Almuawi, ${ }^{1}$ Mohammed Daboos, ${ }^{* 1},{ }^{2}$ Ramakrishna Prasad, ${ }^{1}$ \\ 1 Department of Pediatric Surgery, King Abdullah Hospital, Bisha, Saudi Arabia \\ 2 Pediatric Surgery Department, Al-Azhar University, Cairo, Egypt
}

Correspondence*: Dr. Mohammad Daboos MD, Pediatric Surgery Department, Al-Azhar University, Cairo, Egypt. E-mail: daboosmohammad@gmail.com

\begin{abstract}
KEYWORDS
Pedunculated hemangioma Pediatric liver tumors Infantile hepatic hemangioma
\end{abstract}

\section{INTRODUCTION}

Infantile Hepatic Hemangioma (IHH) is the most common benign liver tumor in the first year of life with a female preponderance.[1,2] Most IHHs are not present at birth but become apparent days to a few weeks after birth. They rapidly proliferate in the first 6-10 months of life followed by slow involution that can take up to 10 years. $[3,4]$

Giant hepatic hemangiomas $(>4 \mathrm{~cm}$ in diameter) are rare but can lead to life-threatening complications such as consumptive thrombocytopenic coagulopathy (Kasabach-Merritt syndrome), anemia, hemorrhage, and high output congestive heart failure.[4] This report demonstrates the importance of early diagnosis and prompt management of such complications, especially in neonates.

\section{CASE REPORT}

A 2-day-old $(3.2 \mathrm{~kg})$ full-term male neonate, a prenatally diagnosed case of a large intra-abdominal cystic mass and born by a simple vaginal delivery, was ventilated immediately after birth because of respiratory distress. The routine initial laboratory data showed anemia (Hb $11.4 \mathrm{~g} / \mathrm{dl}$ with Hct 33.6\%), thrombocytopenia $(120,000 / \mathrm{ml})$, slightly elevated liver enzymes (AST $130 \mathrm{U} / 1$, ALT $112 \mathrm{U} / 1$ ), and hyperbilirubinemia $(2.6 \mathrm{mg} / \mathrm{dl})$.

CT scan of the abdomen revealed an ill-defined large sized $(10.5 \times 8.6 \times 6.3 \mathrm{~cm})$ multilocular cystic lesion with thick enhancing walls, occupying the right side of the abdomen and diagnosed radiologically as a huge mass related to the liver with all bowel loops were pushed to the other side (Fig.1).

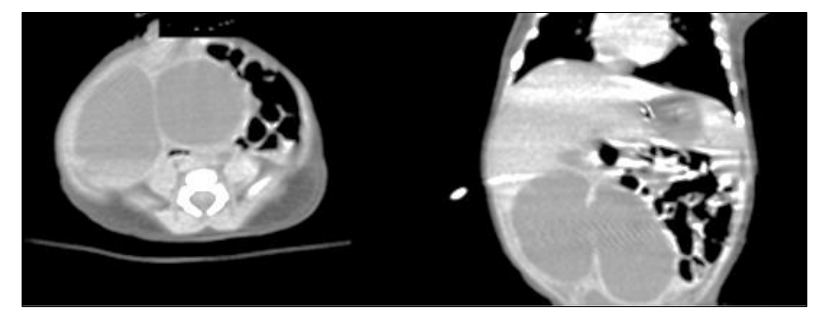

Figure 1: CT scan of the abdomen revealed multilocular huge cystic mass related to the liver with thick enhancing wall.

Due to the worsening of clinical status and fearing an abdominal compartment syndrome, laparotomy was performed through a right supraumbilical abdominal incision. A huge mass was found arising from the 
undersurface of the right lobe of the liver with a pedunculated vascular connection extended across the plane of the falciform ligament (Fig.2A, 2B). The consistency of the mass was soft to firm. The mass was excised with ligation of tumor pedicle, and preservation of hepatic tissue. The tumor size was more than $9 \mathrm{~cm}$ and weighed 125grams (Fig.2C). Postoperatively the baby was ventilated for two more days and later had a smooth postoperative recovery. Feeding was established fully by the third postoperative day. All postoperative laboratory tests were within the normal range.

Histopathology demonstrated extensive foci of hemorrhage and coagulated blood with cavernous vascular spaces. The vascular spaces were formed by fibrous septa lined by a single layer of benign endothelial cells. These findings were most consistent with an infantile hepatic hemangioma. Follow-up US at 3rd post-operative week showed no residual masses. The baby is on our follow-up in the outpatient clinic and doing fine.

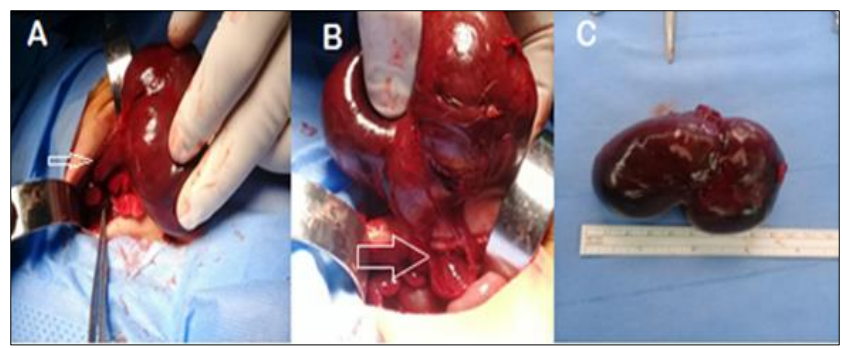

Figure 2: Intra operative finding of giant pedunculated hepatic hemangioma. A) Arrow pointed to the tumor pedicle. B) Excision of the tumor with preservation of liver tissue, the arrow pointed to the tissue of the right hepatic lobe. C) The excised tumor.

\section{DISCUSSION}

$\mathrm{HH}$ are benign vascular tumors present at birth and distinct from vascular malformations. Giant $\mathrm{HH}$ is rarely reported; hence, its exact incidence rate remains undetermined.[5] Occasionally these lesions are either asymptomatic or present relatively innocuously as an abdominal mass or abdominal distention. However, these lesions can manifest with significant symptoms, including hepatomegaly, high output congestive heart failure $(\mathrm{CHF})$, respiratory distress, hypothyroidism, and anemia. Main complications include torsion and infarction due to a long and mobile pedicle, Kasabach-Merritt syndrome may occur, which is characterized by acute thrombocytopenia, microangiopathic hemolytic anemia, and consumptive coagulopathy. [6]

The US picture of IHH can be highly variable. Solitary lesions can have a heterogeneous echogenicity, and the Doppler spectral analysis can show a variety of flow patterns. On CT with intravenous contrast, IHH will either enhance diffusely or show rim enhancement that is followed by gradual filling of the center of the lesion. In one series the $\mathrm{CT}$ enhancement pattern was correlated to the size of the lesions. Lesions less than $1 \mathrm{~cm}$ enhanced homogeneously in the arterial phase. Lesions greater than $2 \mathrm{~cm}$ demonstrated peripheral rim enhancement. Unfortunately, the classic enhancement patterns are not always present in $\mathrm{IHH}$, which can make the radiologic diagnosis more difficult.[7] In the present case, the CT scan couldn't confirm the preoperative diagnosis of hepatic hemangioma may be due to its huge size and presence of blood clotting in vascular spaces. MRI is emerging as the single most useful modality to show both the location of the hemangioma, its flow pattern, and the structure.[8] MRI is considered an excellent diagnostic modality but unfortunately was not available in the index case.

Management of hepatic hemangioma depends on the severity of the presenting symptoms and the size of the lesion. Asymptomatic lesions are usually monitored with serial US or MRI, and no specific therapy is instituted until symptoms develop. Infants who present with $\mathrm{CHF}$, coagulopathy, or respiratory compromise require intervention. [4] The usual initial treatment is prednisone or prednisolone at a dose of $2-3$ $\mathrm{mg} / \mathrm{kg} /$ day.

The symptomatic response rate to corticosteroids is reported to be about $45 \%$. If steroids are ineffective, some IHHs have shown a response to vincristine (VCR) at a weekly dose of $1-2 \mathrm{mg} / \mathrm{m} 2$ for 2 weeks.[4] Propranolol, however, is rapidly becoming the mainstay of treatment with an excellent safety profile. Its proposed mechanisms of action include vasoconstriction, inhibition of angiogenesis, and induction of apoptosis.[9] In the index case, the patient developed early respiratory distress due to large abdominal mass, thrombocytopenia, anemia, and bowel compression; moreover, the radiological findings could not help in the diagnosis, therefore, that authors decided for surgery with suspicion of huge non-specific hepatic mass.

Embolization can also be offered to the symptomatic hemangiomas.[10] Resection should be considered if the hemangioma is confined to a single lobe or pedunculated lesion. In this situation, a survival rate of $92 \%$ has been reported, even if the clinical situation is complicated by $\mathrm{CHF} .[4,11]$ Bartsch et al., reported a case of giant fetal hepatic hemangioma. The newborn developed anemia, thrombocytopenia, and disseminated intravascular coagulation (DIC) with progressive congestive heart failure within $24 \mathrm{hrs}$ of the birth. An emergent extended left lobectomy was necessitated which proved life-saving for the neonate.[11] Similarly in the index case, the baby developed thrombocytopenia, anemia, bowel compression, and ventilated due to respiratory difficulty, thus ne- 
cessitated urgent surgical intervention to avoid deterioration.

In conclusion, giant hepatic hemangiomas may become life threatening due to significant mass effect on respiration and bowel, associated thrombocytopenia, and anemia. Adequate monitoring and support are mandatory in such cases and surgical excision at times becomes lifesaving.

Acknowledgements: We thank the case parents for permission to present the images and findings.

\section{REFERENCES}

1. Leon M, Chavez L, Surani S. Hepatic hemangioma: What internists need to know. World J Gastroenterol. 2020; 26:11-20.

2. Riley MR, Garcia MG, Cox KL,William BK, John Jr. Hepatic infantile hemangioendothelioma with unusual manifestations. J Pediatr Gastroenterol Nutr. 2006; 42:109-13.

3. Ji Y, Chen S, Xiang B,Xu Z, Jiang X, LiuX, et al. Clinical features and management of multifocal hepatic hemangiomas in children: a retrospective study. Sci Rep. 2016; 6:31744.

4. Andrews SW, Kane B, Richard J. Hendrickson; Lesions of the liver: In Ashcraft's Pediatric Surgery (7th ed), Holcomb GW, Murphy JP, Peter SD. Saunders Elsevier; 2020:1030-35.

5. Jiao-ling L, Xiu-Ping G,Kun-Shan C,Qiu-Ming H, XiaoFen L, Bo-Yang Y, etal. Huge fetal hepatic Hemangioma: prenatal diagnosis on ultrasound and prognosis.BMC Pregnancy Childbirth. 2018; 18:2 Available from: https://doi.org/10.1186/s12884-0171635-7.
Conflict of Interest: None declared

Source of Support: Nil

Consent to Publication: Author(s) declared taking informed written consent for the publication of clinical photographs/material (if any used), from the legal guardian of the patient with an understanding that every effort will be made to conceal the identity of the patient, however it cannot be guaranteed.

Author Contributions: Author(s) declared to fulfil authorship criteria as devised by ICMJE and approved the final version.

6. Burrows PE, Dubois J, Kassarjian A. Pediatric hepatic vascular anomalies. Pediatr Radiol. 2001;31:533-45.

7. Feng ST, Chan T, Ching AS, Guo HY, Fan M, Meng QF, et al. CT and MR imaging characteristics of infantile hepatic hemangioendothelioma. Eur J Radiol. 2010; 76:e24-e29.

8. Lu M, Greer ML. Hypervascular multifocal hepatoblastoma: dynamic gadolinium-enhanced MRI findings indistinguishable from infantile hemangioendothelioma. Pediatr Radiol. 2007; 37:58791.

9. Bosemani T, Puttgen KB, Huisman TA, Tekes A. Multifocal infantile hepatic hemangiomas--Imaging strategy and response to treatment after propranolol and steroids including review of the literature. Eur $\mathrm{J}$ Pediatr. 2012;171:1023-28.

10. Kullendorff CM, Cwikiel W, Sandstrom S. Embolization of hepatic hemangiomas in infants. Eur $\mathrm{J}$ Pediatr Surg. 2002;12:348-52.

11. Bärtsch EM, Paek BW, Yoshizawa J, Goldstein RB, Ferrell LD, Coakley FV, et al. Giant fetal hepatic hemangioma. Fetal Diagn Ther. 2003; 18:59-64. 